\title{
Allogeneic stem cell transplantation for bone regeneration of a nonunion defect in a canine
}

This article was published in the following Dove Press journal:

Veterinary Medicine: Research and Reports

8 October 2013

Number of times this article has been viewed

\author{
Kevin Yaneselli' \\ Andrea Filomeno' \\ Gabriel Semiglia' \\ Carolina Arce' \\ Analía Rial ${ }^{2}$ \\ Natalia Muñoz ${ }^{2}$ \\ María Moreno ${ }^{2}$ \\ Kent Erickson ${ }^{3}$ \\ Jacqueline Maisonnave' \\ 'Universidad de la República, Facultad \\ de Veterinaria, Montevideo, Uruguay; \\ ${ }^{2}$ Laboratory for Vaccine Research, \\ Department of Biotechnology, \\ Instituto de Higiene, Facultad de \\ Medicina, Universidad de la República, \\ Montevideo, Uruguay; ${ }^{3}$ University of \\ California, Davis, CA, USA
}

Correspondence: Jacqueline Maisonnave Facultad de Veterinaria, Lasplaces I550, Montevideo CP II600, Uruguay

Tel $+5982628 \quad 1303$

Fax +59826280130

Email jacmaiso@gmail.com

\begin{abstract}
Nonunion bone defects occur frequently with local pain, functional limitations, muscular atrophy, and fistulas due to osteomyelitis. The application of mesenchymal stem cells (MSCs) could improve regeneration of bone following bone defects. The objective of the present study was to evaluate the treatment of a nonunion defect due to chronic osteomyelitis in a greyhound female dog with allogeneic adipose tissue-derived mesenchymal stem cells (AT-MSCs). The implanted cells were adherent to plastic, were of fibroblast type, and expressed the canine stem cell markers $\mathrm{CD} 90^{\text {low }}, \mathrm{CD} 44^{\text {high }}$, and $\mathrm{CD}^{-} 5^{-}$. Cell therapy consisted of five percutaneous weekly injections of $2 \times 10^{6}$ allogeneic AT-MSCs into the bone defect (total of $10 \times 10^{6}$ AT-MSCs). The patient was evaluated clinically and radiologically for up to 1 year. The results were clinical improvement, a light lameness score of 1 at week 16, return to use of its forearm, no pain, and increased muscular mass. No signs of osteomyelitis were observed radiologically and clinically there were no fistulas. There was no evidence of local or systemic adverse reactions caused by the alloimplants. The clinical relevance of the cell therapy contributing to repair of bone defects in small animals is a very promising future alternative. These results may have an important impact in new regenerative treatments for animal and human orthopedics.
\end{abstract}

Keywords: allogeneic, AT-MSCs, treatment, nonunion, canine

\section{Introduction}

Bone is a tissue that has the ability to heal itself when fractured, but when bone defects are large or there is osteomyelitis, it fails to heal. The traditional treatment for osteomyelitis is broad spectrum antibiotic (ATB) therapy and a surgical debridement of the affected bone. Vascularization is decreased in fractures with osteomyelitis due to the infection and the damaged tissues. All the necrotic tissue should be removed and the periosteum perforated to increase the irrigation of the area. These procedures can be dangerous if too much tissue is removed and bone regeneration may not occur. ${ }^{1-4}$ The expanding need for bone reconstruction is paired with the growth of interest in tissue engineering. When bone defects fail to heal, cellular therapy with mesenchymal stem cells (MSCs) may be another therapeutic option.

It has been demonstrated that canine MSCs derived from adipose tissue (AT) express the MSCs markers CD39, CD44, CD73, CD90, CD117, and CD148a, do not express the hematopoietic markers CD34 and CD45, and possess the same capacity as bone marrow-derived mesenchymal stem cells (BM-MSCs) to differentiate into adipogenic, chondrogenic, and osteogenic lineages. ${ }^{5,6}$

The use of autologous and allogeneic MSCs led to increased healing of critical sized bone defects. ${ }^{7,8}$ MSCs implants enhanced the repair of experimentally 
induced critical sized bone defects. ${ }^{7,9}$ The application of adipose tissue-derived mesenchymal stem cells (AT-MSCs) in canine clinical cases has been poorly documented. In one report, a dog with a nonunion bone defect received a percutaneous implant of autologous BM-MSCs, and after 8 weeks the patient was able to use its leg. ${ }^{10}$

MSCs exhibit three characteristics - angiogenesis, ${ }^{11}$ multipotentiality, ${ }^{5,12}$ and immunomodulation ${ }^{9,13}$ - that makes them very attractive and suitable for tissue engineering purposes. Those cells could be used as an alternative to traditional treatment in veterinary medicine. ${ }^{12,14-16}$

\section{Clinical case}

A dog was admitted to the Veterinary Hospital of the University of Uruguay. It could not use its left forearm and had several fistulas on it. A nonunion fracture was observed clinically with muscular atrophy and pain in the area. Radiographs showed a nonconsolidated fracture of the left radius and cubitus with sites of osteogenesis, osteolysis, and osteomyelitis. No records were obtained for how old the lesion was since the dog was abandoned in the street. The animal was treated with the ATB Clindamycin for a month before it arrived at the Veterinary Hospital. Nevertheless, no improvement was observed by the new owners, and the fistulas and not being able to bear any weight in the affected forearm persisted. We hypothesized that the application of allogeneic AT-MSCs in the site of nonunion could generate a proper microenvironment for bone regeneration due to AT-MSCs role in angiogenesis, immunomodulation, and osteogenesis. The purpose of the study was to evaluate the treatment of a nonunion fracture and osteomyelitis with allogeneic AT-MSCs.

\section{Materials and methods}

\section{Patient}

A female greyhound dog approximately 3 years old (dental age assessment) had a nonunion of the radius and cubitus, presumably due to an exposed fracture that resulted in a chronic osteomyelitis (Figure 1).

\section{AT-MSCs processing (isolation, expansion, and cryopreservation)}

The allogeneic AT-MSCs came from the MSCs Bank at the Veterinary School, Uruguay. The AT-MSCs donor was a 10 year old female dog admitted for an ovariectomy. The AT extraction protocol was previously authorized by the National Experimental Animal Ethic Commission "Comisión Honoraria de Experimentación Animal.” The primary culture of AT-MSCs was previously described ${ }^{5,17,18}$ and briefly, $4 \mathrm{~g}$ of subcutaneous AT was collected, subjected to enzymatic digestion with collagenase type I at $1 \mathrm{mg} / \mathrm{mL}\left(\mathrm{Gibco}^{\circledR}\right.$, Life Technologies, Carlsbad, CA, USA). It was then centrifuged at $300 \mathrm{~g}$ for 5 minutes and the pellet was resuspended in Minimal Essential Medium $\left(\mathrm{Gibco}^{\circledR}\right.$ ) with 10\% fetal bovine serum and $2 \%$ penicillin-streptomycin $\left(\mathrm{Gibco}^{\circledR}\right)$. The cells were seeded in a T25 flask and incubated at $37^{\circ} \mathrm{C}$ with $5 \% \mathrm{CO}_{2}$. Cultures were observed daily and medium was changed every 48 hours. When the cells reached $80 \%$ confluency, they were harvested and expanded at $2 \times 10^{4}$ cells $/ \mathrm{cm}^{2}{ }^{18}$ The expanded AT-MSCs were cryopreserved according to Martinello et $\mathrm{al}^{5}$.

\section{Quality control of the AT-MSCs}

The MSCs used for therapy were fibroblastic, adherent to plastic, and were used between passages 2 and $4\left(\mathrm{P}_{2}-\mathrm{P}_{4}\right)$.

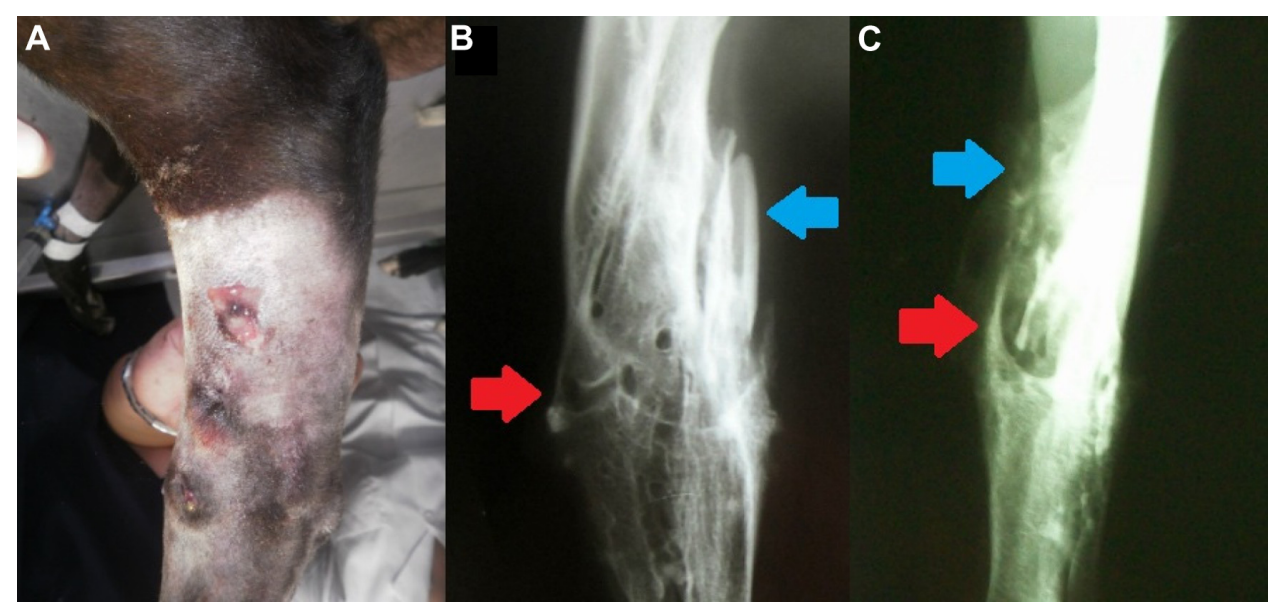

Figure I Affected forearm, day 0.

Notes: (A) Fistulas. (B) Lateral radiograph. (C) Frontal radiograph. The red arrows show the site of nonunion. The blue arrows show bone fragments and sites of osteogenesis and osteolysis. 
The method used for isolation was described by Martinello et $\mathrm{al}^{5}$. The adherent cells were characterized by anti-CD flow cytometry.

\section{Flow cytometry analysis of canine stem cells}

Characterization of canine stem cells was conducted by flow cytometry. Canine AT-MSCs $\left(\mathrm{P}_{2}-\mathrm{P}_{4}\right)$ were detached by incubation in cold phosphate-buffered saline (PBS) with $1 \mathrm{mM}$ ethylenediaminetetraacetic acid (EDTA) for 20 minutes on ice, and then scraped. Cells were washed with fluorescenceactivated cell sorting (FACS) buffer (PBS, 1\% bovine serum albumin, $1 \mathrm{mM}$ EDTA) and immunostained with $10 \mu \mathrm{L}$ of each of the following antibodies: fluorescein isothiocyanate conjugated anti-CD45/LCA (CD45RO, clone UCHL1, Acris Antibodies, San Diego, CA, USA), phycoerythrin conjugated anti-CD90 (THY1, clone 5E10, antibodies-online, Atlanta, GA, USA), allophycocyanin conjugated anti-CD44 (clone IM7, Leinco Technologies Inc., St Louis, MO, USA), and their respective isotype controls (BD Bioscience, San Diego, CA, USA). After incubation for 30 minutes at $4^{\circ} \mathrm{C}$ in the dark, cells were washed thrice with FACS buffer before analysis. Acquisition was performed using a FACS Canto II (BD Bioscience) and data were later on analyzed using FlowJo software (Tree Star, Inc., Ashland, OR, USA).

\section{AT-MSCs processing for application}

The cells were prepared as previously described, harvested when $80 \%$ confluent, and implanted between $\mathrm{P}_{2}$ and $\mathrm{P}_{4}{ }^{5,17,18}$ Each implant consisted of $2 \times 10^{6}$ allogeneic AT-MSCs resuspended in $3 \mathrm{~mL}$ of PBS.

\section{Patient's care pre and post MSCs implants}

All the procedures were in compliance with the guiding principles "Care and Use of Animals" policy of the Universidad de la República, Facultad de Veterinaria, Uruguay. For each of the implants, the animal was sedated intravenously with Acepromazine $1 \%(0.01 \mathrm{mg} / \mathrm{kg})$, midazolam $0.5 \%(0.25 \mathrm{mg} / \mathrm{kg})$, and ketamine $5 \%(5 \mathrm{mg} / \mathrm{kg})$. The patient also received $2.5 \mathrm{~mL}$ penicillin-streptomycin $(200,000 \mathrm{IU})$, potassium penicillin $\mathrm{G}$, procaine penicillin $\mathrm{G}(600,000 \mathrm{IU})$, and $0.5 \mathrm{~g}$ streptomycin subcutaneously. One week before the MSCs therapy started, the animal was treated with Clindamycin $(11 \mathrm{mg} / \mathrm{kg}$ orally every 12 hours) for 4 weeks.

Before each implant, the forearm was shaved from the humerus to the carpus, and thoroughly washed and cleaned with $70 \%$ ethyl alcohol. The affected area was located by palpation (it was painful) and the area of greater bone lyses identified by a radiograph. The 20 gauge needles were introduced until they reached the bone. The AT-MSCs were injected percutaneously (three injections of $1 \mathrm{~mL}$ each around the nonunion site), with a total of $10 \times 10^{6}$ cells in five implants. The efficacy of the treatment was evaluated clinically and radiologically over 1 year.

\section{Lameness assessment}

The lameness was assessed by clinical observation based in the matrix score 1 to 10 (with increasing numbers equating to more lameness) described by Summer-Smith ${ }^{19}$ where 0 is normal, 1 is occasionally rejects bearing weight, 9 is bears weight when is standing up but rejects it when in movement, and 10 is not bearing weight at all. After the first implant the animal was clinically evaluated weekly up to week 5 , and then studied clinically and radiologically at weeks 4,8 , and 16 , and at 1 year. The clinical evaluation consisted of detecting signs of local inflammation (redness, edema, pain, increase in local temperature), enlarged lymph nodes, and presence of fistula. Signs of systemic reactions were also evaluated (body temperature, cardiac and respiratory frequency), as well as mucosae, skin color, and lymph nodes.

\section{Results}

The cells implanted were fibroblastic and adherent to plastic. Flow cytometry characterization of canine AT-MSCs used in the treatment showed expression of the canine stem cell markers CD90 low, $\mathrm{CD} 44^{\text {high }}$, and CD45- (Figure 2).

The dog had a positive clinical outcome as assessed by a lameness score. At week 0 it had severe lameness (score 10), at week 4 it had medium lameness (score 7 to 8 ), at week 8 it limped when walking but when standing up, it put all its weight on the affected leg (score 3 to 4 ) and had no fistulas, and at week 16 it had light lameness (score 1) and no fistulas (Figure 3A). At 1 year posttreatment it did not show fistulas, had no pain, and continued with a lameness score of 1 . The radiological evaluation at week 16 showed a reabsorption process, regeneration, and bone remodeling with partial consolidation of the fracture (Figure 3B and 3C). The radiographs (not shown) taken at 1 year posttreatment did not show much difference to those at 16 weeks.

At 8 and 16 weeks, and 1 year after MSCs therapy, no adverse reactions were observed as there was no local or systemic evidence of inflammation. Also, after 8 weeks the owner did not observe signs of pain or lack of appetite. After 16 weeks the animal was more active and continued that way until the last evaluation at 1 year. 

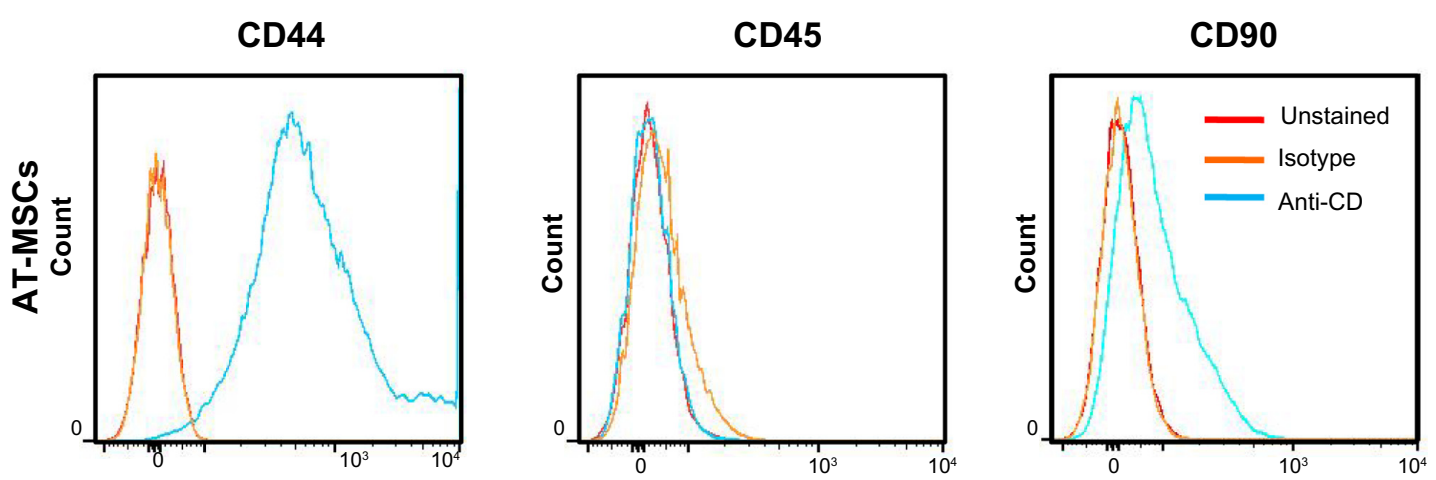

Figure 2 Flow cytometry characterization of canine stem cells derived from adipose subcutaneous abdominal tissue.

Notes: Histogram plots show unstained cells (red lines), cells stained with control isotype antibodies (orange lines), and cells stained with allophycocyanin conjugated antiCD44, fluorescein isothiocyanate conjugated anti-CD45, or phycoerythrin conjugated anti-CD90 antibodies (blue lines).

Abbreviations: $C D$, cluster of differentiation; AT-MSCs, mesenchymal stem cells derived from adipose tissue.

\section{Discussion}

Nonunion associated osteomyelitis and an infectious process is usually associated with severe fractures. The traditional treatment recommended is a broad spectrum ATB and it is often necessary to remove surgically the necrotic and/or sequestered bone under general anesthesia and stimulate angiogenesis in the affected site. ${ }^{1,3}$ Vascularization of the osteomyelitis bone is decreased due to the infection and the damaged tissues. These procedures can be dangerous if too much tissue is removed and bone regeneration may not occur. ${ }^{1-4}$ Usually patients with osteomyelitis require ATB therapy for weeks or months. Clindamycin is a broad spectrum ATB commonly used in osteomyelitis, ${ }^{20-22}$ and was the one used in this study prior to arrival at the Veterinary Hospital and during the first 4 weeks of cellular therapy. The ATB therapy alone used before arrival was not sufficient to clear the osteomyelitis. When the ATB therapy fails an alternative is cellular therapy with percutaneous injections of stem cells that requires only light sedation and is less invasive.

The International Society of Cellular Therapy (ISCT) states that in order to consider cells as human MSCs they must be fibroblastic, adherent to plastic, immunotypified, and have multilineage differentiation capacity. ${ }^{5,6,23}$ Recently, Martinello et $a l^{5}$ characterized canine stem cells derived from visceral adipose tissue. Stem cells were CD90 $0^{\text {low }}, \mathrm{CD} 44^{\text {high }}$, CD140 $0^{\text {high }}, \mathrm{CD} 117^{\text {int }}, \mathrm{CD}^{2} 4^{-}$, and CD45-. Takemitsu et al ${ }^{6}$ also found that the canine AT-MSCs were CD $90^{\text {low }}, \mathrm{CD} 44^{\text {high }}$, $\mathrm{CD} 29^{\text {high }}, \mathrm{CD}^{-} 4^{-}$, and $\mathrm{CD}^{2} 5^{-}$. Likewise, we found that the AT-MSCs used in this study were CD90 $0^{\text {low }}, \mathrm{CD} 44^{\text {high }}$, and CD45- Even though we did not differentiate them in vitro, the MSCs used in this study complied with all the other characteristics stated by the ISCT.

The number of MSCs used depends on the size and type of lesion. A total of $10 \times 10^{6}$ allogeneic AT-MSCs were transplanted at the site of nonunion in the greyhound dog.

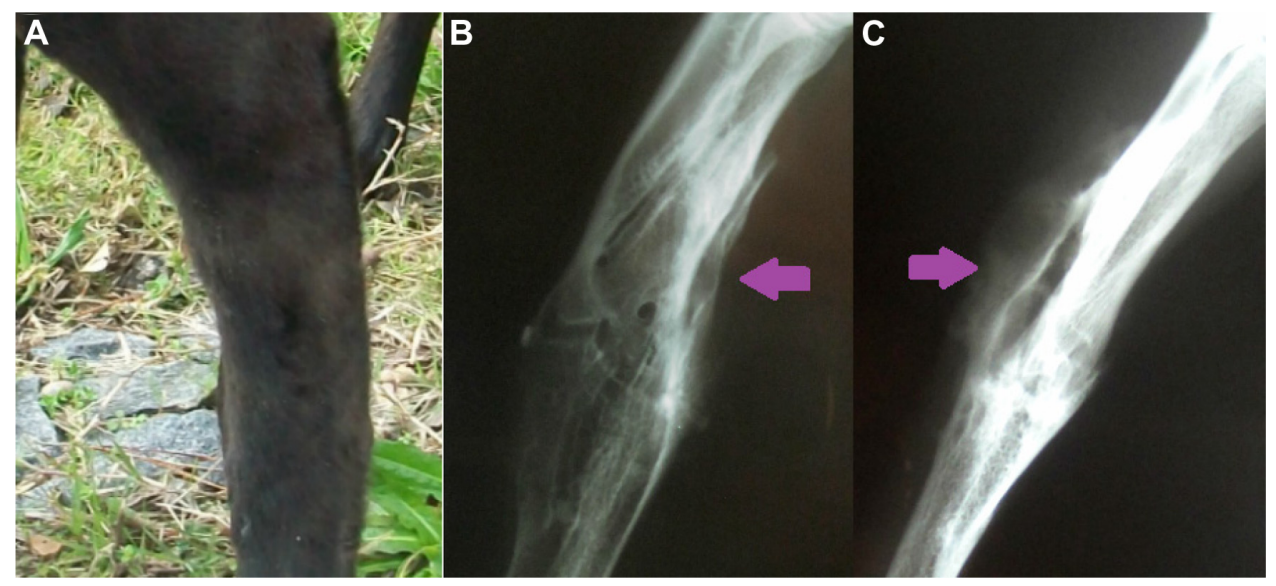

Figure 3 Affected forearm, week 16.

Notes: (A) No fistulas. (B) Lateral radiograph. (C) Frontal radiograph. The violet arrows show areas of reabsorption and bone regeneration. 
Arinzeh et $\mathrm{al}^{9}$ applied $37 \times 10^{6}$ allogeneic BM-MSCs on $21 \mathrm{~mm}$ induced femur fractures of 20 adult dogs. In canine models of spinal cord neuronal lesions, Jung et al ${ }^{12}$ applied $10 \times 10^{6}$ allogeneic BM-MSCs. However, Semiglia et $\mathrm{al}^{10}$ were successful in treating a natural nonunion defect with a single percutaneous injection of $1 \times 10^{6}$ autologous BMMSCs. There are few reports on the use of MSCs in chronic osteonecrosis pathologies. Allogeneic BM-MSCs systemically (intravenously) applied had stopped the osteonecrosis process. ${ }^{9,25,26}$ These authors attributed the good results to the characteristics of immunomodulation, angiogenesis, and osteoprogenitor nature of the MSCs. ${ }^{24,25}$ Even though the routes of application of the MSCs were different, the results obtained in the present report can be compared as the infection of the bone was resolved, no more fistulas appeared, and the animal could bear weight in the affected forearm. Another chronic bone disease, osteonecrosis of the femoral head in humans, was successfully treated with BM-MSCs. ${ }^{26,27}$ As described by Zhao et al, ${ }^{27} 2 \times 10^{6}$ autologous BM-MSCs were implanted locally on the necrotic femoral head and there were reduced symptoms, osteonecrosis reverted, and there was no adverse reaction with the use of MSCs. Despite the differences in the treatments reported by other authors in number of cells and type of bone pathology, there is a point of agreement with the hypothesis stated in this study that the MSCs promote recovery of the patient. Also, these authors ${ }^{26,27}$ used clinical observation and radiology evaluations and the results were improvement in the quality of life of the patients. Normally, a noncomplicated bone fracture can heal in 8 weeks. In the present study there was an improvement in the patient's quality of life, with clinical evidence (no fistulas, light lameness, and could run) observed at 16 weeks and radiological evidence of bone regeneration. Similar studies had similar results between weeks 8 and 16 posttreatment in fractures treated with MSCs associated with a ceramic scaffold. . $^{7}$

The animal of the present report did not show adverse reactions to the AT-MSCs allografts (no local or systemic inflammatory response) at 8 and 16 weeks and 1 year posttreatment. These results are consistent with the findings of several other authors who, in canines, used implants of allogeneic ${ }^{9,12}$ and xenogeneic ${ }^{8}$ MSCs at 16 and 12 weeks, respectively, and noticed clinical improvement of the orthopedic defects and no evidence of adverse rejections. Arinzeh et $\mathrm{al}^{9}$ detected allogenic MSCs at the bone defects at 8 weeks but not at 16 weeks. They attributed it to a process of apoptosis, but more studies are needed to prove it. In the present case we did not study how long the MSCs stayed at the site of implant, but from a clinical point of view, no adverse local or systemic effects were noticed. The improvement observed was significantly more from the clinical point of view than the radiological one. This could be due to the fibrous or fibrocartilage tissue filling the chronic bone defect that is not detected on X-rays until it is mineralized.

\section{Conclusion}

Cellular therapy applied on the nonunion fracture contributed to healing of the fistulas and bone regeneration and the patient started using the forearm. The repeated use of allogeneic AT-MSCs implants did not produce adverse reactions in the patient. As this study lacked an untreated control, we cannot be sure that only the cellular therapy was responsible for the clinical improvement. To best of our knowledge, this is the first report on the use of allogeneic MSCs based therapy of a natural clinical nonunion associated with osteomyelitis.

\section{Acknowledgments}

The authors would like to express their gratitude to the technician, Marcelo Cabrera, for his technical assistance in tissue culture. We are also grateful to the owners that agreed to try an innovative regenerative medicine treatment in their dog.

\section{Disclosure}

The authors report no conflicts of interest in this work.

\section{References}

1. Budenki LJ, Smith MM. Infecciones ortopédicas. In: Slatter D, editor. Tratado de Cirugía en Pequeños Animales. 3rd ed. Buenos Aires: Inter-Médica; 2006:2130-2145. Spanish.

2. Carek PJ, Dickerson LM, Sack JL. Diagnosis and management of osteomyelitis. Am Fam Physician. 2001;63(12):2413-2420.

3. Schulz K. Fundamento de la cirugía ortopédica y manejo de las fracturas. In: Fossum T, Hedlund C, Jhonson A, Schulz K, Seim H, Willard R, Bahr A, Carroll G, editors. Cirugía en pequeños animales. 3rd ed. Barcelona: Elseiver Mosby; 2009:1333-1356. Spanish.

4. Brady R, Leid J, Costerton J, Shirtliff M. Osteomyelitis: clinical overview and mechanisms of infection persistence. Clin Microbiol Newsl. 2006;28(9):66-72.

5. Martinello T, Bronzini I, Maccatrozzo L, et al. Canine adipose-derivedmesenchymal stem cells do not lose stem features after a long-term cryopreservation. Res Vet Sci. 2011;91(1):18-24.

6. Takemitsu H, Zhao D, Yamamoto I, Harada Y, Michishita M, Arai T. Comparison of bone marrow and adipose tissue-derived canine mesenchymal stem cells. BMC Vet Res. 2012;8:150.

7. Bruder SP, Kraus KH, Goldberg VM, Kadiyala S. The effect of implants loaded with autologous mesenchymal stem cells on the healing of canine segmental bone defects. J Bone Joint Surg Am. 1998;80(7):985-996.

8. Niemeyer P, Szalay K, Luginbuhl R, Sudkamp NP, Kasten P. Transplantation of human mesenchymal stem cells in a non-autogenous setting for bone regeneration in a rabbit critical-size defect model. Acta Biomater. 2010;6(3):900-908.

9. Arinzeh TL, Peter SJ, Archambault MP, et al. Allogeneic mesenchymal stem cells regenerate bone in a critical-sized canine segmental defect. $J$ Bone Joint Surg Am. 2003;85A(10):1927-1935. 
10. Semiglia G, Filomeno A, Zunino J, et al. Use of autologous mesenchymal bone marrow derived cells on a canine non-union femoral fracture (preliminary results). 2nd Annual North American Veterinary Regenerative Medicine Association Conference; June 2-4, 2011. Kentucky, USA.

11. Imanishi Y, Saito A, Komoda H, et al. Allogenic mesenchymal stem cell transplantation has a therapeutic effect in acute myocardial infarction in rats. J Mol Cell Cardiol. 2008;44(4):662-671.

12. Jung DI, Ha J, Kang BT, et al. A comparison of autologous and allogenic bone marrow-derived mesenchymal stem cell transplantation in canine spinal cord injury. J Neurol Sci. 2009;285(1-2):67-77.

13. Wan C, He Q, Li G. Allogenic peripheral blood derived mesenchymal stem cells (MSCs) enhance bone regeneration in rabbit ulna criticalsized bone defect model. J Orthop Res. 2006;24(4):610-618.

14. Mimeault M, Batra SK. Recent progress on tissue-resident adult stem cell biology and their therapeutic implications. Stem Cell Rev. 2008;4(1):27-49.

15. Pacini S, Spinabella S, Trombi L, et al. Suspension of bone marrowderived undifferentiated mesenchymal stromal cells for repair of superficial digital flexor tendon in race horses. Tissue Eng. 2007;13(12): 2949-2955.

16. Strauer BE, Schannwell CM, Brehm M. Therapeutic potentials of stem cells in cardiac diseases. Minerva Cardioangiol. 2009;57(2): 249-267.

17. Yaneselli K, Mirazo J, Semiglia G, et al. Terapia Regenerativa: Comportamiento celular in vitro de células madre mesenquimales de origen animal. 7mas Jornadas Técnicas Veterinarias (Montevideo). 2011;1:62-63. Spanish.

18. Yaneselli K, Filomeno A, Mirazo J, Arce C, Semiglia G, Maisonnave J. Comportamiento in vitro de células madre mesenquimales derivadas de tejido adiposos canino y equino (resultados preliminares). Simposio Latinoamericano de Tecnología de Cultivos Celulares. Santa Fe, Argentina. 2012:48. Spanish.

19. Sumner-Smith G. Lameness. In: Sumner-Smith G, Binnington AG, Cockshutt JR, Du JF, Du Lg, Miller CW, Prieur WD, editors. Decision Making in Small Animal Orthopaedic Surgery. Philadelphia: BC Decker; 1988:10-11.
20. Frank D, Montsko G, Juricskay I, et al. Clindamycin release determined by high performance liquid chromatography from a novel low-cost local drug delivery system: a new potential treatment option for chronic osteomyelitis. J Chemother. 2011;23(5):282-284.

21. Paakkonen M, Peltola H. Simplifying the treatment of acute bacterial bone and joint infections in children. Expert Rev Anti Infect Ther. 2011;9(12):1125-1131.

22. Vidaillac C, Parra-Ruiz J, Winterfield P, Rybak MJ. In vitro pharmacokinetic/pharmacodynamic activity of NXL103 versus clindamycin and linezolid against clinical Staphylococcus aureus and Streptococcus pyogenes isolates. Int J Antimicrob Agents. 2011;38(4): 301-306.

23. Horwitz EM, Le Blanc K, Dominici M, et al; International Society for Cellular Therapy. Clarification of the nomenclature for MSC: The International Society for Cellular Therapy position statement. Cytotherapy. 2005;7(5):393-395.

24. Handschel J, Meyer U. Infection, vascularization, remodelling - are stem cells the answers for bone diseases of the jaws? Head Face Med. 2011;7:5.

25. Kikuiri T, Kim I, Yamaza T, et al. Cell-based immunotherapy with mesenchymal stem cells cures bisphosphonate-related osteonecrosis of the jaw-like disease in mice. J Bone Miner Res. 2010;25(7): $1668-1679$.

26. Gangji V, De Maertelaer V, Hauzeur JP. Autologous bone marrow cell implantation in the treatment of non-traumatic osteonecrosis of the femoral head: Five year follow-up of a prospective controlled study. Bone. 2011;49(5):1005-1009.

27. Zhao D, Cui D, Wang B, et al. Treatment of early stage osteonecrosis of the femoral head with autologous implantation of bone marrow-derived and cultured mesenchymal stem cells. Bone. 2012;50(1):325-330.
Veterinary Medicine: Research and Reports

\section{Publish your work in this journal}

Veterinary Medicine: Research and Reports is an international, peer-reviewed, open access journal publishing original research, case reports, editorials, reviews and commentaries on all areas of veterinary medicine. The manuscript management system is completely online and includes a very quick and fair peer-review system.

\section{Dovepress}

Visit http://www.dovepress.com/testimonials.php to read real quotes from published authors. 